Review

\title{
Admiral Nurse Case Management within Enhanced Health in Care Homes
}

Zena Aldridge ${ }^{1,2,{ }^{*}}$, Karen Harrison Dening ${ }^{1,2}$

1. Dementia UK, 7thFloor, One Aldgate, London EC3N 1RE, UK; E-Mails: zena.aldridge@dementiauk.org; Karen.Harrison-Dening@dementiauk.org

2. De Montfort University, Gateway House, Leicester LE1 9BH, UK.

* Correspondence: Zena Aldridge; E-Mail: zena.aldridge@dementiauk.org

Academic Editor: David G Smithard

OBM Geriatrics

2021, volume 5, issue 2

doi:10.21926/obm.geriatr.2102167
Received: February 15, 2021

Accepted: April 07, 2021

Published: April 21, 2021

\section{Abstract}

The United Kingdom's (UK) older population is higher than the global average. Over the next 20 years, England will see an increase in the number of older people who have higher levels of dependency, dementia, and comorbidity many of whom may require 24-hour care. Currently it is estimated that $70 \%$ of residents in nursing and residential care homes either have dementia on admission or develop it whilst residing in the care home. The provision of high-quality care for this population is a challenge with a lack of consistency in the provision of primary care and specialist services and a known gap in knowledge and skills. The NHS Long Term Plan aims to move care closer to home and improve out of hospital care which includes people who live in care homes by introducing Enhanced Health in Care Homes (EHCH). However, such services need to be equipped with the correct skill mix to meet the needs of the care home population. Admiral Nurses are specialists in dementia care and are well placed to support the delivery of $\mathrm{EHCH}$ and improve access to specialist support to care home residents, their families, care home staff and the wider health and social care system. This paper discusses current gaps in service provision and how both the $\mathrm{EHCH}$ framework, and the inclusion of Admiral Nurses, might redress these and improve outcomes.

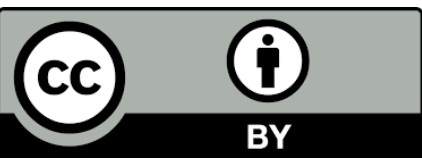

(C) 2021 by the author. This is an open access article distributed under the conditions of the Creative Commons by Attribution License, which permits unrestricted use, distribution, and reproduction in any medium or format, provided the original work is correctly cited. 


\section{Keywords}

Dementia; Admiral Nurses; care homes; integrated systems; enhanced health in care homes; palliative care

\section{Background}

\subsection{Ageing Population}

People aged over 80 years old equate to $15 \%$ of the world's total population [1]. This increase in the proportion of older people has major health, social care and economic implications [1]. The United Kingdom's (UK) older population is higher than the global average, in 2017 approximately $18 \%$ of the UK population were aged 65 years or over and this figure is projected to grow to almost $21 \%$ by 2027 [2]. Projections suggest that in 50 years' time there will be an expected additional 8.6 million people over 65 years old in the UK [2]. It is also predicted that the number of people aged over 85 will increase to 3.5 million by 2043 equating to $5 \%$ of the total UK population. It is important that health and care systems adapt and respond to meet this changing demographic to better manage resources and consider interventions which both prevent and manage chronic conditions that are inevitable in an ageing population [3].

Older people often have complex health and social care needs and have an increased risk of developing dementia [4]. On average people living with dementia are likely to have 4.6 chronic conditions besides dementia [5], other studies indicate that $61 \%$ of people with dementia have at least three comorbid conditions [6, 7]. Comorbidities can include conditions such as chronic obstructive pulmonary disease, chronic cardiac failure, hypertension, diabetes, sensory impairment, vascular or heart disease and musculoskeletal disorders and depression [8-11]. Over the next 20 years, England will see an increase in the number of older people who have higher levels of dependency, dementia, and comorbidity [12]. Whilst dementia is not a normal nor inevitable part of ageing [13], age is the greatest risk factor of developing dementia therefore as the population ages the number of people living with dementia is set to rise [4].

\subsection{Dementia}

It is estimated that there are 885,000 people in the UK living with dementia and numbers are projected to increase by $80 \%$ to 1.6 million people by 2040 [14]. Dementia is an umbrella term used to describe a syndrome with a group of symptoms that are characterised by memory loss, behavioural changes, and loss of cognitive and social functioning caused by progressive neurological disorders [15]. There are over 200 subtypes of dementia, but the most common are Alzheimer's disease, vascular dementia, Lewy Body disease, mixed dementia (often a combination of Alzheimer's and Vascular) and Frontotemporal dementia [16]. Although the majority of people with dementia live in the community approximately one third of people with dementia live in care homes [17]. It is estimated that $70 \%$ of residents in nursing and residential care homes either have dementia on admission or develop it whilst residing in the care home $[17,18]$, which equates to an estimated 311,730 people with dementia residing in UK care homes [17]. 


\subsection{Care Homes}

Care homes in the UK are categorised as either nursing or residential care homes. Nursing homes offer on-site 24-hour nursing care and support for activities of daily living (ADLs), whereas residential care homes offer 24-hour care to support ADLs, with any nursing needs met by external National Health Service (NHS) community nurses [19-21]. All care homes in the UK are monitored by regulatory bodies within each of the devolved nations to ensure they meet the prescribed standards of care [22].

The provision of high-quality care for the care home population is an international challenge for the sector [23]. Older people admitted to all types of care homes are often frail and have complex needs [24, 25], such as, higher levels of dependency, cognitive impairment, distressed behaviours, multimorbidity, subject to polypharmacy and are frequent users of NHS resources [26]. As a result, they are more likely to be approaching the end of their lives. A study by Kinley et al. [27] found that $56 \%$ of older people admitted to UK care homes died within the first year with the average life expectancy being 24 months for residential care homes without nursing and 12 months for nursing homes [28]. UK care homes, even those providing nursing care, are reliant on NHS primary care services to review the medical and nursing needs of residents, and to access specialist services.

\section{Enhanced Health in Care Homes}

People living in care homes should expect the same level of support as if they were living in their own home. In 2019 the NHS published its Long-Term Plan, which aims to deliver care closer to home and improve out of hospital care [29] which included a framework to provide better support to care home populations through one of the strands of work within the Ageing Well programme of the Long-Term Plan. NHS England \& NHS Improvement [30] propose that to achieve this requires collaborative working between health and social care, third sector and care home partners and have developed a model of Enhanced Health in Care Homes (EHCH). The EHCH model strives to move away from traditional reactive models of care delivery towards proactive care which centres on the needs of individual residents, their families and care home staff [30]. The EHCH model will be delivered through Primary Care Networks (PCN), the key building blocks of the NHS Long-Term Plan that bring together general practices to support integration of health and care systems [29]. The EHCH framework aims to deliver healthcare across seven key areas (See table 1) which include; enhanced primary care support; multi-disciplinary team (MDT) support; high quality palliative and end-of-life care; dementia care and workforce development [30].

Table 1 Core elements and sub elements of refreshed EHCH model (adapted from [30]).

\begin{tabular}{ll}
\hline Care element & Sub-element \\
\hline 1. Enhanced primary care support & - Each care home aligned to a named \\
& PCN, which leads a weekly \\
& multidisciplinary 'home round' \\
& - Medicine reviews \\
- Hydration and nutrition support & - Oral health care
\end{tabular}


- Access to out-of-hours/urgent care when needed

2. Multi-disciplinary team (MDT) support including coordinated health and social care
3.Falls prevention, Reablement, and rehabilitation including strength and balance

4. High quality palliative and end-of-life care, Mental health, and dementia care

5. Joined-up commissioning and collaboration between health and social care

6. Workforce development

7. Data, IT and technology
- Expert advice and care for those with the most complex needs

- Continence promotion and management

- Flu prevention and management

- Wound care - leg and foot ulcers

- Helping professionals, carers, and individuals with needs navigate the health and care system

- Rehabilitation/reablement services

- Falls, strength, and balance

- Developing community assets to support resilience and independence

- Palliative and end-of-life care

- Mental health care

- Dementia care

- Co-production with providers and networked care homes

- Shared contractual mechanisms to promote integration (including Continuing Healthcare)

- Access to appropriate housing options

- Training and development for social care provider staff

- Joint workforce planning across all sectors

- Linked health and social care data sets

- Access to the care record and secure email Better use of technology in care homes

This paper will now discuss how the model of Admiral Nurse case management can support PCNs in achieving the ambition for $\mathrm{EHCH}$.

\section{Admiral Nurse Case Management}

Admiral Nurses are specialist dementia nurses who, through a biopsychosocial case management approach recognise the interactions between biological, psychological, and social factors that influence wellness and disease [31]. Case management enables the Admiral Nurse to work across health and social care systems to deliver clinical support to families affected by dementia who have complex needs. The Admiral Nurse model aims to deliver case management across the life course of dementia [32] from peri diagnosis to end-of-life and then through to post bereavement support 
of family members (Figure 1) and can be adapted to support people with dementia (and their families and care staff) in which ever setting they may find themselves. Admiral Nurses adopt a range of strategies, approaches and interventions to meet the holistic needs of families affected by dementia. The person-centred approach to dementia care [33] is one of the cornerstones of their practice whilst recognising and supporting the relationships that surround the person with dementia. Family focused (relationship centred) interventions embrace shared decision-making, while also maintaining and supporting autonomy in the person with dementia for as long as is possible [34]. In more recent years the relationship-centred model of care has become more prominent with the emergence of triadic perspectives of care that include the person with dementia, their families and carers, and the professionals that care for them [35, 36]. Relationship-centred care is a model advocated for the care home setting in which people receive care in an enriched environment encompassing not only the relationships between residents, their families and carers and care home staff, but extends to the relationships between the care home and wider health and social care system [37]. 
We asked our Admiral Nurses to map how they work across the NHS Well Pathway for Dementia to deliver expert clinical, practical and emotional support for families. This is what they told us:

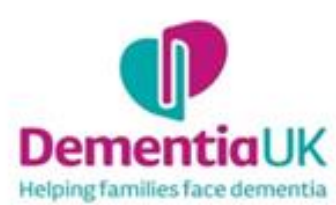

Dying Well

\section{Preventing Well}

\section{Diagnosing Well}

- Raising awareness
- Reducing stigma
- Health promotion
- Disseminating
information
- Carer education
- Community
engagement
- Preventative
management of risks
tohealth, eg. falls,
delirium, poor
nutrition, reduced
mobility, incontinence,
polypharmacy,
depression etc.

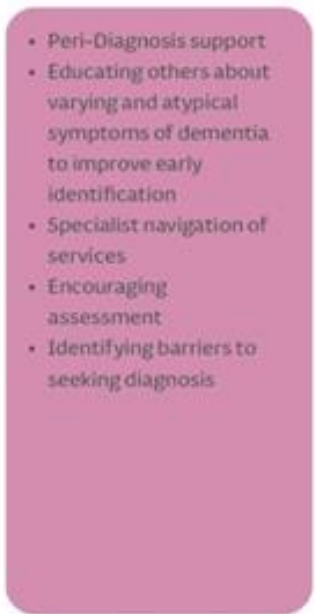

SupportingWel

\section{- Specialist}

bio-psycho-socia

assessment

Psycho-social

interventions

Family focussed

interventions

Managing and ldentifying

co-morbidities and

complexneeds

Person-centred care

planning

- Developing coping

strategies

- Non-pharmacologica

management of

psychological symptons

of dementia
Living Well

- Positive risktaking

- Managing transition

- Advanced care planning

- Building resilience

- Symptom management

- Crisis prevention

- Relationship support

Managing grief, loss and

bereavement

Enabling access to life

outside caring

Promoting/enabling

inclusion and

participation
- Promoting independence
Diflicitconversations

Difficult comversations

Improved

access to preferred

place of death

Recognition of end of

life

- Pre and post

bereavement

emotional support and

counselling for families

- Identification of

prognostic indicators

Symptom identification

e.g.pain identification and

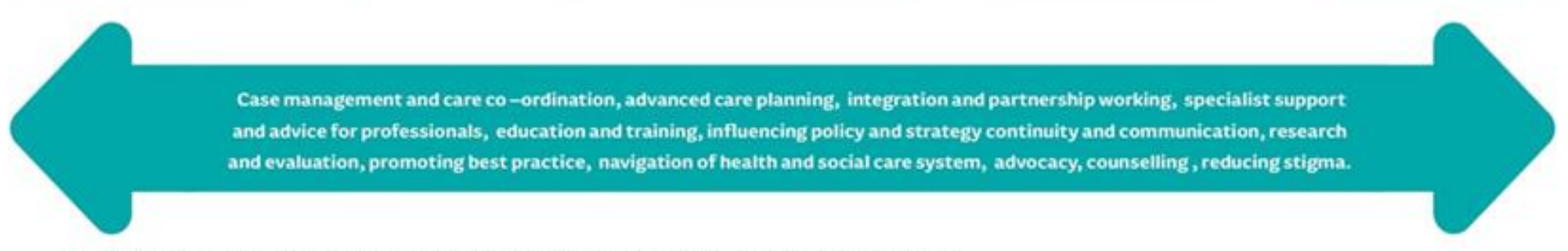

'https://www.england.nhs.uk/mentalhealth/wp-content/upioads/sites/29/2016/03/dementia-well-pattwway.pdf

Figure 1 Admiral Nurse interventions across NHS England Dementia well pathway. 
Therefore, as well as working directly with families affected by dementia with complex needs, Admiral Nurses provide consultancy and support to generalist colleagues through education, supervision and mentorship to enable the best possible dementia care. Consultancy requires close working and collaboration with all stakeholders and care providers to deliver comprehensive care for the whole family. A case management approach ensures expertise from all areas is harnessed and care delivered in a consistent, efficient and cost-effective way [38, 39]. The Admiral Nurse ABC model of case management applied to MDT or PCN locality working seeks to integrate health and social care services as well as those provided by the private and charity sectors to support families affected by dementia, wherever the person with dementia may reside (see figure 2) [40].

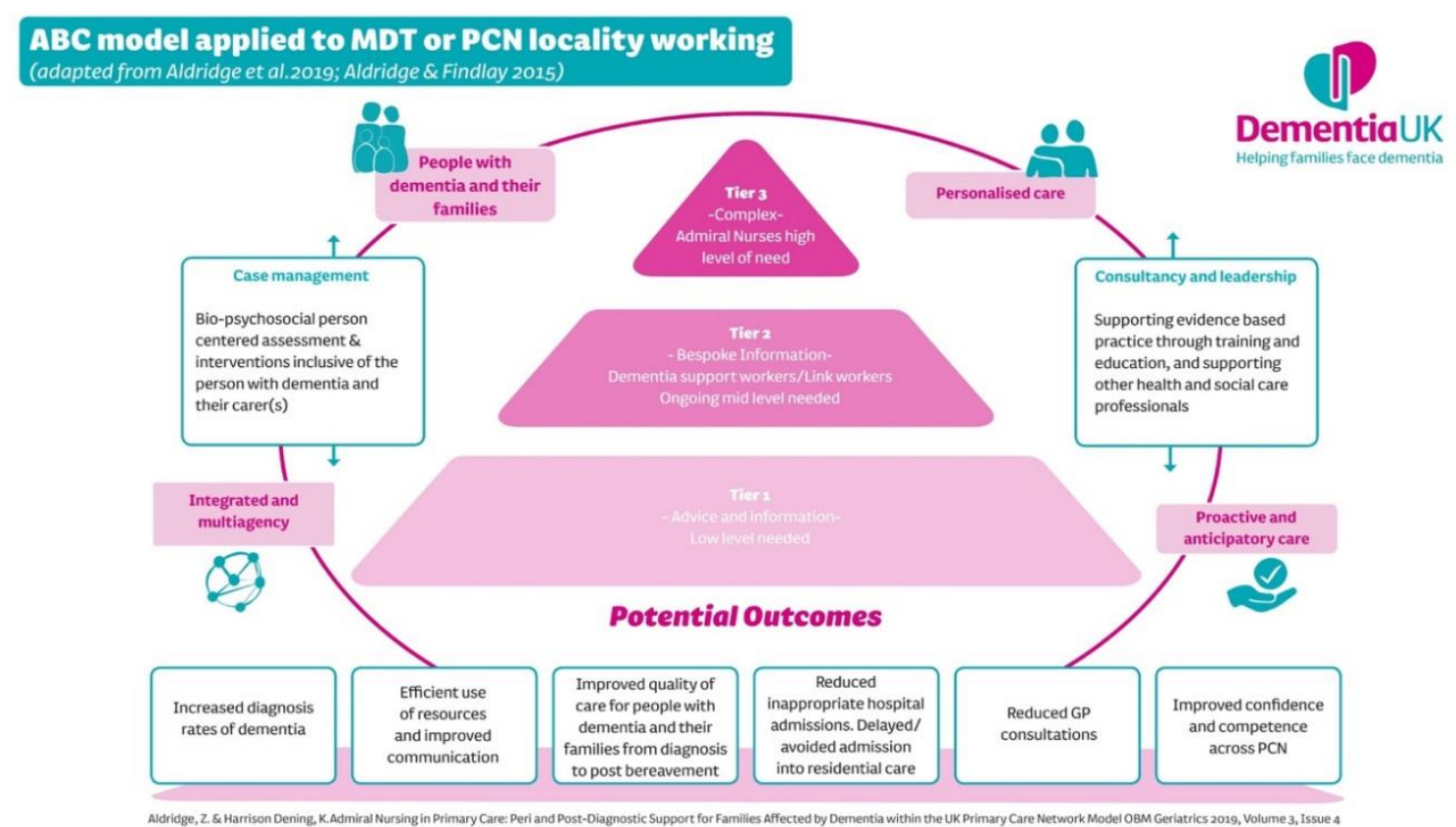

Figure 2 ABC Model applied to MDT or PCN locality working [19].

Currently there is little consistency in the way care is delivered in to care homes due to fragmented commissioning and so may often be driven by crisis management [41-43]. Care homes are reliant on NHS primary care services to review the often-complex medical needs of residents, and to access specialist services [29]. However, access to general practitioners (GP) and specialist healthcare service varies considerably [44], with some GP practices offering regular ward rounds alongside as required visits, whilst others only visit when requested [45]. Evidence suggests that for many primary and secondary health services the provision of support to care homes has not been seen as a priority [44]. The EHCH approach offers an opportunity to redress this inequity by offering a model of best practice for commissioners, healthcare providers and stakeholders to follow and reflects the proactive and integrated approach that is central to Admiral Nurse case management. An adaptation of the Admiral Nurse $A B C$ model integrated into $E H C H$ could affect positive outcomes against the EHCH framework [30] (see figure 3). This paper now highlights some of the expected outcomes that Admiral Nursing within an $\mathrm{EHCH}$ framework could impact positively upon. 
ABC model of Admiral Nursing applied to Enhanced Health in Care Homes

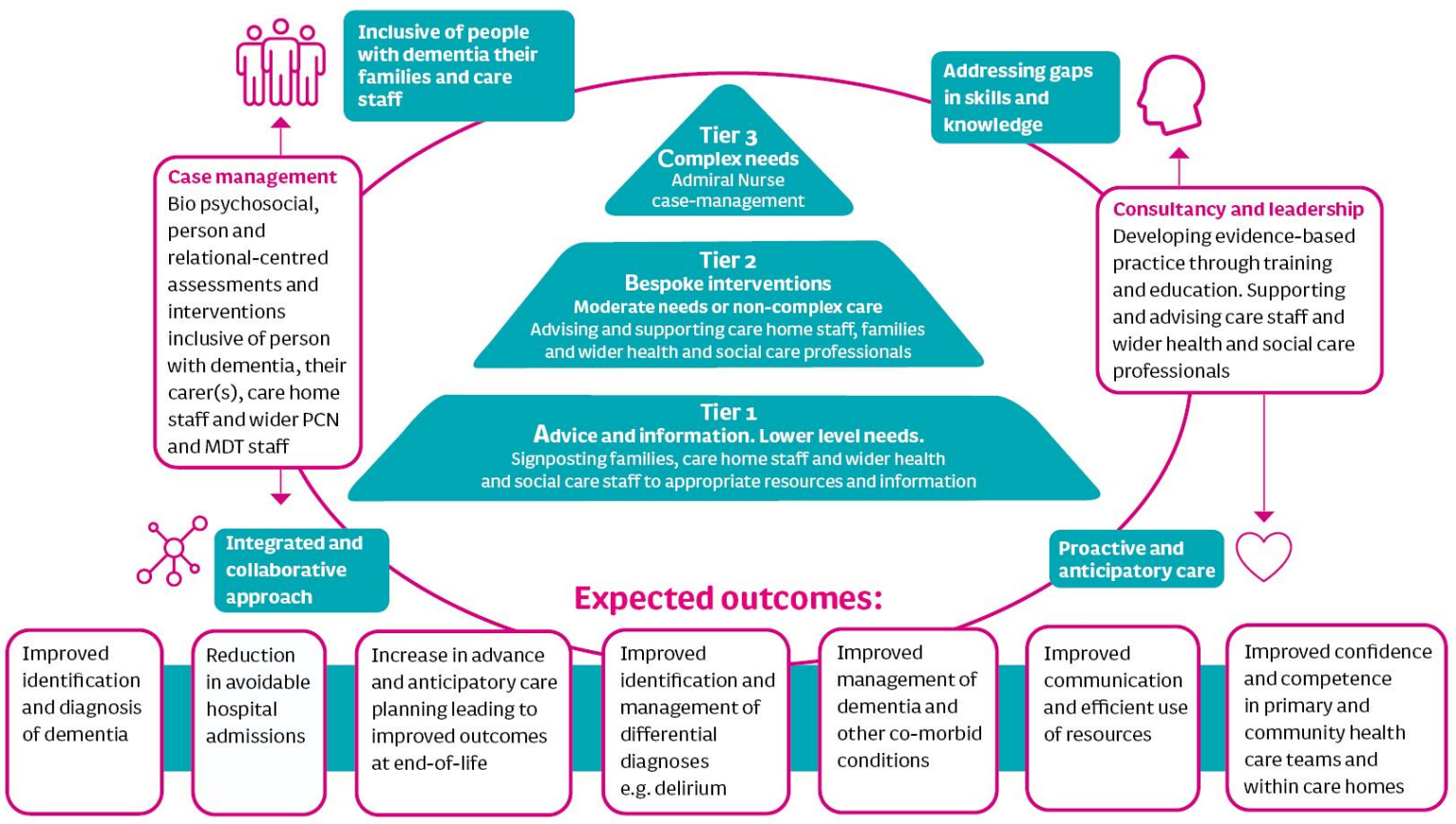

Figure 3 The ABC Model of Admiral Nursing model applied to Enhanced Health in Care Homes.

\section{Identification and Diagnosis of Dementia}

The National Institute of Health and Clinical Excellence (NICE) dementia guideline [46] recommends people thought to have dementia should receive timely access to an assessment with several benefits identified, such as, access to early interventions and management for comorbidities [47]. However, dementia diagnosis rates in care homes are known to be particularly poor [18]. It is recognised that this may be in part due to skills and resource gap in primary care and within care homes which can negatively impact the recognition of dementia symptoms, and subsequent access to assessment and diagnosis [18]. Although, conversely, some professionals still question whether there is actually any value in a diagnosis of dementia at all $[18,48]$. Consequently, Admiral Nurses can educate, advise and support care home staff and primary care colleagues to identify symptoms, support screening and coordinate dementia assessments both within primary care and through onward referral to specialist memory assessment services. As a consequence of improving identification and diagnosis of dementia in care home residents, the person with dementia, their families and care home staff can be enabled to consider pre-emptive decisionmaking and setting goals of care [49]. Similarly, the dementia diagnosis can inform the treatment and management of other comorbid conditions which can reduce the risk of avoidable hospital admissions and improve quality of life [50]. 


\section{Preventable Hospital Admissions}

Dementia is a life-limiting, progressive condition for which there is no cure [51] and is now the leading cause of death in England and Wales [52]. Historically, most people with dementia have died in acute hospitals, however, this is changing with approximately $58 \%$ of such deaths now being in care homes [53]. Whilst this may be seen as a positive step forward and evidence to suggest people are dying in their preferred place of death, there are still a high number of emergency hospital admissions of people with dementia in their last year of life, rising significantly in the months before death $[54,55]$. This is due to a lack of direct preventative interventions in the care homes in managing both multimorbidity and intercurrent conditions [51]. Multimorbidity, frailty and dementia represents the most common 'disease pattern' found among the care home population, characterised by a complex interaction of each [51]. People with dementia do not always have their comorbid conditions managed as well as those without dementia, which often leads to a high number of hospital admissions with longer lengths of stay and greater treatment costs [56]. They are also less likely to have access to the usual primary care services and resources available to other community dwelling older people [57]. Admiral Nurse case managers can support care home staff and the primary care team to manage and monitor comorbid conditions or any intercurrent acute condition superimposed on dementia to reduce any avoidable hospital admissions. This may involve several interventions by the Admiral Nurse, for example, educating care home staff and the wider MDT to understand the interplay of dementia with other physical conditions and support differentiating between conditions, such as, dementia, delirium and depression, so enabling speedier and more appropriate access to community based care and treatment and avoid escalation [58].

Similarly, they can offer support and guidance on prognosis and the trajectory of dementia which may reduce inappropriate and burdensome transitions to hospital which often result in poorer quality end-of-life care [59]. There is evidence to suggest that people in the advanced "terminal" stages of dementia are often exposed to overly aggressive, burdensome or futile treatments and consequently there is a need for expertise in dementia care at end-of-life [60]. Such hospital admissions may be reduced or prevented if swift action is taken when a resident deteriorates and therefore enable access to timely treatment or symptom control in the care home setting [41, 51]. Therefore the inclusion of Admiral Nurse within $\mathrm{EHCH}$ may support pre-emptive discussions and decision-making.

\section{Advance and Anticipatory Care Planning for End-of-Life}

NICE dementia guidelines [46] recommend a palliative care approach to dementia, commencing at the point of diagnosis through to end-of-life [46]. A palliative care approach regards dying as a normal process and aims to provide the best possible quality of life until death for the person with the terminal condition $[61,62]$. Essential to a palliative approach is pre-emptive care and a timely recognition of the dying phase and avoiding unnecessarily burdensome treatments [63, 64].

The European Association of Palliative Care (EAPC) white paper proposed a series of domains and recommendations for palliative care in relation to people with dementia [64] and one domain centred on advance care planning (ACP). ACP is a process that supports adults at any age or stage of health in understanding and sharing their personal values, life goals, and preferences regarding future medical care. The goal of ACP is to help ensure that people receive care that is consistent 
with their values, goals and preferences during serious and chronic illness [65]. However, supporting the development of an ACP directly with the person with dementia will depend upon their capacity to do so.

The point in the life course of the disease ACP is offered is important and the sooner after diagnosis, the better $[51,66]$. There are several barriers to ACP for people with dementia [43] and few-have an ACP in place when they move into a care home when many are in the advanced stages of in the disease and may have already lost capacity $[67,68]$. Thus, ACP moves more to a shared decision-making approach involving families and in supporting best interests' decisions [66]. There is often a reliance on substitute or proxy decision-makers, usually family members who participate in decision-making on behalf of those who are no longer able to make decisions for themselves in relation to their financial and/or health and care needs [69] whom play an important role in end-oflife decision-making [70].

Whilst there has been focus on the potential benefits of ACP for people with dementia [39, 7173], there has been limited focus on meeting the support needs of substitute or proxy decisionmakers $[70,72,74]$. Decision-making on behalf of a person with impaired capacity can be an emotional and burdensome process [75], therefore to ameliorate some of these challenges for families and care staff alike Admiral Nurses can offer skilled facilitation of ACP, anticipatory care planning and support shared decision-making by adapting their communication and approach according to each family's needs [76] alongside supporting care home staff and other healthcare professionals to determine the most appropriate options to consider.

\section{Differential Diagnoses}

As discussed earlier, when a person experiences memory loss or other features that might indicate the development of dementia, this requires assessment. There are several other conditions that can mimic symptoms of dementia, such as, vitamin deficiencies, infections, delirium, depression and metabolic disorders-which may be reversible and should be ruled out at an early stage $[58,77]$. As well as ensuring any reversible causes of a person's symptoms are identified, it is also important to distinguish between the "3D's": dementia, delirium and depression which a person may be experienced singularly or concurrently at any one time [58]. These are all serious conditions that are common in older people and have similar presentations, which may lead to each condition going undetected and untreated [78, 79]. Equally, these conditions occur more frequently in the care home population [80-82]. Stewart et al. [82] report high levels of unmet need in respect of these conditions with high levels of behavioural symptoms and psychotropic medication use. The Admiral Nurse could not only support care home staff and primary care teams to enable a differential diagnosis between dementia, depression and delirium and expedite treatment pathways [56] for each but also support better assessment, treatment and management of behavioural symptoms and thus avoid inappropriate use of antipsychotic medications [58].

\section{Dementia and Comorbidities}

Left untreated and unmanaged comorbid conditions can cause pain, distress and worsening health [51]. Equally, dementia and comorbidities can interact with one another causing either complication with treatment or an acceleration or exacerbation of one or more of the individual diseases $[10,11,77,83]$. For example, a person may have both dementia and diabetes; poorly 
managed blood sugar levels can impact on cognition and cognition can impact upon a person ability to manage their diet and treatment regimens. However, it is suggested that the recognition of symptoms and subsequent diagnosis of comorbidities experienced by people with dementia is underestimated due to the difficulties people living with dementia may have in communicating any new symptoms [83]. Similarly there is a propensity to attribute any symptoms to a known, existing condition, an effect called "diagnostic overshadowing", whereby symptoms are attributed to one condition as opposed to being seen as an interaction with other comorbid conditions or indeed the manifestation of a new condition [77, 84]. An example of such diagnostic overshadowing is often seen when a person with dementia becomes distressed, and changes in behaviour being solely attributed to a worsening or progression of dementia as opposed to considering other possible causes such as for example pain, delirium or depression. Admiral Nurses are able to guide care home staff and other health professionals to consider differential diagnoses and suggest assessments, interventions and treatments that can reduce the negative effects that residents may be experiencing and moreover improve their quality of life [85].

\section{Communication and Resource Utility}

As previously discussed, the overarching philosophical approaches to care in care homes are those of relational [37] and person-centred models [33] which seek to meet the holistic needs of both residents and embrace family members [86]. This differs from other areas of healthcare which may be more readily sited within a biomedical model of care with the primary focus being on the health needs of the 'patient' as opposed to the 'resident' [87]. There is evidence to suggest that doctors are more likely to make decisions based on the functional status of the patient rather than the expressed wishes of family or ACP [88]. Furthermore, despite the known complexities and comorbidities of people with dementia, there remains a propensity to deliver care that focusses on singular conditions and diseases, which increases the risk of burdensome treatments and polypharmacy $[5,10,77]$.

Whilst GPs have clinical authority, they may have limited knowledge of care home residents and therefore rely on the input of family members and/or care staff to ascertain the normal presentation of the person with dementia and to alert them to deterioration [89]. In using a biopsychosocial model of case management Admiral Nurses consider the complex needs of the residents in totality by incorporating relational, person-centred and biomedical models of care a when communicating and coordinating care $[40,85]$. Such an approach improves consistency across services to promote clearly defined goals of care so that the person with dementia receives the right care at the right time, whilst taking their wishes and preferences into account and ensuring they are not exposed to futile treatments.

\section{Confidence and Competence to Care}

Care home staff often provide care for residents with complex needs as a result of a variety of conditions, including dementia. The nature of dementia care can be demanding of their knowledge and skills and also emotionally challenging [90]. Rivett and colleagues [90] also identified that a lack of adequate support and limited training opportunities for care home staff may contribute to high levels of staff turnover in this area. However, Goodman et al. [89] identified that when a care home resident is approaching their end-of-life there is often uncertainty about the roles and 
responsibilities of the care home staff, the families and primary care professionals. Despite the GP having clinical authority they may have limited knowledge of the resident and therefore rely upon the input of family carers and/or the care home staff to inform decision-making [89]. Consequently, given the high prevalence of people with dementia living in care homes there is an imperative for the care home workforce to demonstrate their competence by meeting residents needs in a variety of ways. Yet there is currently no consistent model of specialist support for care homes in the UK and it has been identified that as a consequence of the increasing multimorbidity of the care home population, the expertise that is required may be beyond that of some GPs [26]. Furthermore, such complexity can result in people with dementia requiring different levels of care which may require them to move to a different care setting if their needs cannot be met within their current care home, the Admiral Nurse may offer support that minimises the need to move the person with dementia or support a transition to a more appropriate setting should it be required [56].

Therefore, delivering the $\mathrm{EHCH}$ framework will require careful consideration of the skill mix required to ensure the needs of care home residents are adequately served within this new model of care [40]. Reconfiguration of the current workforce will not address the gaps in skills and knowledge and there is an urgent need to consider dementia specialist roles, such as Admiral Nursing, within PCN's and integrated multi-disciplinary teams to address this current gap [40].

\section{Conclusion}

For too long care homes have been isolated from the wider health and social care system despite their vital role in providing care for some of the most vulnerable members of society. With increased rhetoric and political drivers to push forward the agenda of health and social care integration across England there must be a recognition of the gaps that exist within the workforce and strategies to redress these. There is growing momentum to address the inequalities faced by care home residents through the implementation of the EHCH model to be delivered via PCN's. Whilst this is to be welcomed, there is an urgent requirement to consider the complex needs of the care home micro population and ensure facilitation of $\mathrm{EHCH}$ uses appropriately skilled and knowledgeable clinician(s). There is already a known gap in the knowledge and skills in dementia care within PCN's. The inclusion of Admiral Nursing within this new model of care offers an opportunity to embed the specialist clinical knowledge and skills required to redress this and improve outcomes for people with dementia, their families, care staff and the wider health and social care system.

\section{Author Contributions}

ZA conceived the article and structure. The paper was co-authored by ZA and KHD.

\section{Competing Interests}

The authors have declared that no competing interests exist.

\section{References}

1. United Nations. World population ageing [Internet]. New York: United Nations; 2015 [cited 2021 February 14th]. Available from: https://www.un.org/en/development/desa/population/publications/pdf/ageing/WPA2015 R 
eport.pdf.

2. Office of National Statistics. Overview of the UK population: An overview of the UK: How its changed, why it's changed and how its projected to change in the future [Internet]. Titchfield and London: Office of National Statistics; 2018 [cited 2021 February 14th]. Available from: https://www.ons.gov.uk/peoplepopulationandcommunity/populationandmigration/populatio nestimates/articles/overviewoftheukpopulation/november2018.

3. The Government Office for Science. Future of an Ageing Population [Internet]. London: HM Govermeent; 2016 [cited 2021 March 10th]. Available from: https://www.ageing.ox.ac.uk/files/Future of Ageing Report.pdf.

4. Livingston G, Huntley J, Sommerlad A, Ames D, Ballard C, Banerjee S, et al. Dementia prevention, intervention, and care: 2020 report of the Lancet Commission. Lancet. 2020; 396: 413-446.

5. Guthrie B, Payne K, Alderson P, McMurdo ME, Mercer SW. Adapting clinical guidelines to take account of multimorbidity. BMJ. 2012; 345: e6341.

6. Scrutton J, Brancati CU. Dementia and co-morbidities: Ensuring parity of care [Internet]. London: International Longevity Centre London; 2016 [cited 2021 February 14th]. Available from: http://www.ilcuk.org.uk/images/uploads/publication-pdfs/ILCUK Dementia and Comorbidities - Ensuring Parity of Care.pdf.

7. Timmons S, O'Shea E, O'Neill D, Gallagher P, de Siún A, McArdle D, et al. Acute hospital dementia care: Results from a national audit. BMC Geriatr. 2016; 16: 113.

8. Dening T, Milne A. Care homes for older people. In: Oxford textbook of old age psychiatry. 3rd ed. Oxford: Oxford University Press; 2021.

9. Browne J, Edwards DA, Rhodes KM, Brimicombe DJ, Payne RA. Association of comorbidity and health service usage among patients with dementia in the UK: A population-based study. BMJ Open. 2017; 7: e012546.

10. Bunn F, Burn AM, Goodman C, Robinson L, Rait G, Norton S, et al. Comorbidity and dementia: A mixed method study on improving healthcare for people with dementia (CoDem). Southampton: NIHR Journals Library; 2016.

11. Fox C, Smith T, Maidment I, Hebding J, Madzima T, Cheater F, et al. The importance of detecting and managing comorbidities in people with dementia? Age Ageing. 2014; 43: 741-743.

12. Kingston A, Robinson L, Booth H, Knapp M, Jagger C, MODEM project. Projections of multimorbidity in the older population in England to 2035: Estimates from the Population Ageing and Care Simulation (PACSim) model. Age Ageing. 2018; 47: 374-380.

13. van der Flier WM, Scheltens P. Epidemiology and risk factors of dementia. J Neurol Neurosurg Psychiatry. 2005; 76: v2-v7.

14. Wittenberg R, Hu B, Barraza-Araiza L, Rehill A. Projections of older people living with dementia and costs of dementia care in the United Kingdom, 2019-2040 [Internet]. London: London School of Economics and Political Science; 2019 [cited 2021 February 14th]. Available from: https://www.alzheimers.org.uk/sites/default/files/2019-11/cpec report november 2019.pdf.

15. Fratiglioni L, Qiu C. Epidemiology of dementia. In: Oxford textbook of old age psychiatry. 2nd ed. Oxford: Oxford University Press; 2013.

16. Sandilyan MB, Dening T. What is dementia? In: Evidence based practice in dementia for nurses and nursing students. 1st ed. London: Jessica Kingsley; 2019.

17. Prince $M$, Knapp $M$, Guerchet $M$, McCrone P, Prina $M$, Comas-Herrera A, et al. Dementia UK: Update [Internet]. London: Alzheimer's Society; 2014 [cited 2021 February 14th]. Available 
from:

https://www.alzheimers.org.uk/sites/default/files/migrate/downloads/dementia uk update. pdf.

18. Organisation for Economic Co-operation and Development. Care needed: Improving the lives of people with dementia. Paris: OECD Publishing; 2018.

19. Aldridge $Z$, Harrison Dening K. Admiral nursing in primary care: Peri and post-diagnostic support for families affected by dementia within the UK primary care network model. OBM Geriatr. 2019; 3: 16.

20. Wolters A, Santos F, Lloyd T, Lilburne C, Steventon A. Emergency Admissions to hospital from care homes: How often and what for [Internet]? London: The Health Foundation; 2019 [cited 2021 February 14th]Available from: https://reader.health.org.uk/emergency-admissions-tohospital-from-care-homes.

21. Shah SM, Carey IM, Harris T, DeWilde S, Cook DG. Mortality in older care home residents in England and Wales. Age Ageing. 2013; 42: 209-215.

22. Care Quality Commission. The fundamental standards [Internet]. London: Care Quality Commission; 2017 [cited 2021 March 10th]. Available from: https://www.cqc.org.uk/what-wedo/how-we-do-our-job/fundamental-standards.

23. Cooper C, Marston L, Barber J, Livingston D, Rapaport P, Higgs $P$, et al. Do care homes deliver person-centred care? A cross-sectional survey of staff-reported abusive and positive behaviours towards residents from the MARQUE (managing agitation and raising quality of life) English national care home survey. PLoS ONE. 2018; 13: e0193399.

24. Moore DC, Hanratty B. Out of sight, out of mind? A review of data available on the health of care home residents in longitudinal and nationally representative cross-sectional studies in the UK and Ireland. Age Ageing. 2013; 42: 798-803.

25. British Geriatrics Society. A quest for quality in care homes [Internet]. London: British Geriatric Society; 2011 [cited 2020 July 7th]. Available from: https://www.bgs.org.uk/sites/default/files/content/attachment/2019-08-

27/quest quality care homes.pdf.

26. Gordon AL, Franklin M, Bradshaw L, Logan P, Elliott R, Gladman JR. Health status of UK care home residents: A cohort study. Age Ageing. 2014; 43: 97-103.

27. Kinley J, Hockley JO, Stone L, Dewey M, Hansford P, Stewart R, et al. The provision of care for residents dying in UK nursing care homes. Age Ageing. 2014; 43: 375-379.

28. British Geriatric Society. End of life care in frailty: Care homes [Internet]. London: British Geriatric Society; 2020 [cited 2021 March 10th]. Available from: https://www.bgs.org.uk/resources/end-of-life-care-in-frailty-carehomes\#: :text=medications\%20is\%208.-,Identifying\%20need,for\%20care\%20homes\%20with \%20nursing.

29. NHS England. NHS long term plan [Internet]. London: National Health Service; 2019 [cited 2021 February 14th]. Available from: https://www.longtermplan.nhs.uk/wpcontent/uploads/2019/08/nhs-long-term-plan-version-1.2.pdf.

30. NHS England and NHS Improvement. The framework for Enhanced Health in Care Homes [Internet]. London: NHS England and NHS Improvement; 2020 [cited 2021 February 14th]. Available from: https://www.england.nhs.uk/wp-content/uploads/2020/03/the-frameworkfor-enhanced-health-in-care-homes-v2-0.pdf. 
31. George E, Engel L. The clinical application of the biopsychosocial model. Am J Psychiatry. 1980; 137: 535-544.

32. NHS England. The well pathway for dementia [Internet]. London: NHS England; 2015 [Cited 2021 February 14th]. Available from: https://www.england.nhs.uk/mentalhealth/wpcontent/uploads/sites/29/2016/03/dementia-well-pathway.pdf.

33. Kitwood T. Dementia reconsidered: The person comes first. Berkshire, UK: Open University Press; 1997.

34. Daly RL, Bunn F, Goodman C. Shared decision-making for people living with dementia in extended care settings: A systematic review. BMJ Open. 2018; 8: e018977.

35. Keady J, Nolan M. Person-and relationship centred care past, present and future. In: Oxford textbook of old age psychiatry. 3rd ed. Oxford: Oxford University Press; 2021.

36. Quinn C, Clare L, McGuinness T, Woods RT. Negotiating the balance: The triadic relationship between spousal caregivers, people with dementia and admiral nurses. Dementia. 2013; 12: 588-605.

37. Nolan Mr, Brown J, Davies S, Nolan J, Keady J. The senses framework: Improving care for older people through a relationship-centred approach. Getting Research into Practice (GRiP). Report No 2 [Internet]. Sheffield: Sheffield Hallam University; 2006 [cited 2021 March 10th]. Available from: https://core.ac.uk/download/pdf/99946.pdf.

38. Vroomen JM, Bosmans JE, van de Ven PM, Joling KJ, van Mierlo LD, Meiland FJ, et al. Communitydwelling patients with dementia and their informal caregivers with and without case management: 2-year outcomes of a pragmatic trial. J Am Med Dir Assoc. 2015; 16: 800.e1800.e8.

39. Harrison Dening K, Aldridge Z, Pepper A, Hodgkison C. Admiral nursing: Case management for families affected by dementia. Nurs Stand. 2017; 31: 42-50.

40. Aldridge Z, Harrison Dening K. Admiral nursing in primary care: Peri and post-diagnostic support for families affected by dementia within the UK primary care network model. OBM Geriatrics. 2019; 3: 16.

41. Robbins I, Gordon A, Dyas J, Logan P, Gladman J. Explaining the barriers to and tensions in delivering effective healthcare in UK care homes: A qualitative study. BMJ Open. 2013; 3: e003178.

42. Oliver D. Overcoming the challenges to improve health and wellbeing in care homes [Internet]. London: The Kings Fund; 2016 [cited 2021 March 10th]. Available from: https://www.kingsfund.org.uk/blog/2016/10/improve-health-and-wellbeing-care-homes.

43. Harrison Dening K. Advance care planning and people with dementia. In: Advance care planning in end of life care. Oxford: Oxford University Press; 2018.

44. Goodman C, Davies S. Good practice outside care homes. In: Mental health and care homes. Oxford: Oxford University Press; 2011.

45. Illiffe S, Wilcock J, Drennan V, Goodman C, Griffin M, Knapp M, et al. Changing practice in dementia care in the community: Developing and testing evidence-based interventions, from timely diagnosis to end of life (EVIDEM) [Internet]. Southampton: NIHR Journals Library; 2015 [cited 2021 March 10th]. Available from: https://www.ncbi.nlm.nih.gov/books/NBK286118/.

46. National Institute for Health and Care Excellence. Dementia: Assessment, management and support for people living with dementia and their carers [Internet]. London: National Institute for Health and Care Excellence; 2018 [cited 2020 February 14th]. Available from: 


\section{https://www.nice.org.uk/guidance/ng97.}

47. Dementia Action Alliance. Benefits of timely dementia diagnosis: A report for consideration in primary care [Internet]. London: Dementia Action Alliance; 2013 [cited 2021 March 10th]. Available

from: https://www.dementiaaction.org.uk/assets/0000/4970/BENEFITS OF TIMELY DEMENTIA DI AGNOSIS to distribute 2013.pdf.

48. Woods B, Arosio F, Diaz A, Gove D, Holmerová I, Kinnaird L, et al. Timely diagnosis of dementia? Family carers' experiences in 5 European countries. Int J Geriatr Psychiatry. 2019; 34: 114-121.

49. Aldridge Z, Parry-Hughes $M$, Harrison Dening K. Difficult conversations: Nutritional needs of care home residents with advanced dementia. Nurs Resid Care. 2020; 22: 1-7.

50. Robinson L, Tang E, Taylor JP. Dementia: Timely diagnosis and early intervention. BMJ. 2015; 350: h3029.

51. Sampson EL, Harrison Dening K. Palliative and end-of-life care. In: Oxford textbook of old age psychiatry. 3rd ed. Oxford: Oxford University Press; 2020.

52. Office of National Statistics. Dementia and Alzheimer's disease deaths including comorbidities, England and Wales: 2019 registrations [Internet]. London: Office of National Statistics; 2019 [cited $2021 \quad$ February 14th]. Available from: https://www.ons.gov.uk/peoplepopulationandcommunity/birthsdeathsandmarriages/deaths/ bulletins/dementiaandalzheimersdiseasedeathsincludingcomorbiditiesenglandandwales/2019 registrations.

53. Public Health England. National dementia intelligence network and national end of life care intelligence network briefing [Internet]. London: Public Health England; 2016; [cited 2021 February 14th]. Available from: https://assets.publishing.service.gov.uk/government/uploads/system/uploads/attachment da ta/file/733064/Dying with dementia briefing.pdf.

54. Bone AE, Evans CJ, Etkind SN, Sleeman KE, Gomes B, Aldridge M, et al. Factors associated with older people's emergency department attendance towards the end of life: A systematic review. Eur J Public Health. 2019; 29: 67-74.

55. Leniz J, Higginson IJ, Stewart R, Sleeman KE. Understanding which people with dementia are at risk of inappropriate care and avoidable transitions to hospital near the end-of-life: $A$ retrospective cohort study. Age Ageing. 2019; 48: 672-679.

56. Knight $C$, Harrison Dening K. Management of long-term conditions and dementia: The role of the admiral nurse. Br J Community Nurs. 2017; 22: 295-302.

57. Lee L, Lu SK, Hillier LM, Gregg S, Kaufman Carlin G. Improving access to community support and services for persons living with dementia: Integration of home care services into primary carebased memory clinics. Geriatr Gerontol Int. 2019; 19: 81-82.

58. Harrison Dening K. Differentiating between dementia, delirium and depression in older people. Nurs Stand. 2019; 35: 43-50.

59. Chen PJ, Ho CH, Liao JY, Smits L, Hsiung CA, Yu SJ, et al. The association between home healthcare and burdensome transitions at the end-of-life in people with dementia: A 12-year nationwide population-based cohort study. Int J Environ Res Public Health. 2020; 17: 9255.

60. Van der Steen JT, Dekker NL, Gijsberts MJ, Vermeulen LH, Mahler MM. Palliative care for people with dementia in the terminal phase: A mixed-methods qualitative study to inform service development. BMC Palliat Care. 2017; 16: 28. 
61. World Health Organization. WHO definition of palliative care [Internet]. Genève: World Health Organization; 2013 [cited 2021 February 14th]. Available from: http://www.who.int/cancer/palliative/definition/en.

62. Gamondi C, Pott M, Forbes K, Payne S. Exploring the experiences of bereaved families involved in assisted suicide in Southern Switzerland: A qualitative study. BMJ Support Palliat Care. 2015; 5: $146-152$.

63. Midtbust $\mathrm{MH}$, Alnes RE, Gjengedal E, Lykkeslet E. A painful experience of limited understanding: Healthcare professionals' experiences with palliative care of people with severe dementia in Norwegian nursing homes. BMC Palliat Care. 2018; 17: 25.

64. Van der Steen JT, Radbruch L, Hertogh CM, de Boer ME, Hughes JC, et al. White paper defining optimal palliative care in older people with dementia: A Delphi study and recommendations from the European Association for Palliative Care. Palliat Med. 2014; 28: 197-209.

65. Sudore RL, Lum HD, You JJ, Hanson LC, Meier DE, Pantilat SZ, et al. Defining advance care planning for adults: A consensus definition from a multidisciplinary Delphi panel. J Pain Symptom Manage. 2017; 53: 821-832.e1.

66. Harrison Dening K, Sampson EL, De Vries K. Advance care planning in dementia: Recommendations for healthcare professionals. Palliat Care Res Treat. 2019; 12: 1178224219826579.

67. Goodman C, Froggatt K, Amador S, Mathie E, Mayrhofer A. End of life care interventions for people with dementia in care homes: Addressing uncertainty within a framework for service delivery and evaluation. BMC Palliat Care. 2015; 14: 42.

68. Stobbart-Rowlands $M$, Thorn M. Experience of use of advance care planning in care homes. In: Advance care planning in end of life care. 2nd ed. Oxford: Oxford university Press; 2018. pp.128137.

69. Noh H, Kwak J. End-of-life decision making for persons with dementia: Proxies' perception of support. Dementia. 2018; 17: 478-493.

70. Kwak J, Wallendal MS, Fritsch T, Leo G, Hyde T. Advance care planning and proxy decision making for patients with advanced Parkinson disease. Nan Fang Yi Ke Da Xue Xue Bao. 2014; 107: 178185.

71. Wendrich-van Dael A, Bunn F, Lynch J, Pivodic L, Van den Block L, Goodman C. Advance care planning for people living with dementia: An umbrella review of effectiveness and experiences. Int J Nurs Stud. 2020; 107: 103576.

72. Cresp SJ, Lee SF, Moss C. Substitute decision makers' experiences of making decisions at end of life for older persons with dementia: A systematic review and qualitative meta-synthesis. Dementia. 2020; 19: 1532-1559.

73. Dixon J, Karagiannidou M, Knapp $M$. The effectiveness of advance care planning in improving end-of-life outcomes for people with dementia and their carers: A systematic review and critical discussion. J Pain Symptom Manage. 2018; 55: 132-150.e1.

74. Lord K, Livingston G, Cooper C. A systematic review of barriers and facilitators to and interventions for proxy decision-making by family carers of people with dementia. Int Psychogeriatr. 2015; 27: 1301-1312.

75. Barker S, Lynch M, Hopkinson J. Decision making for people living with dementia by their carers at the end of life: A rapid scoping review. Int J Palliat Nurs. 2017; 23: 446-456.

76. Harrison Dening K, Scates C, Lloyd-Williams M. Palliative care in dementia: A fragmented 
pathway? Int J Palliat Nurs. 2018; 24: 585-596.

77. Aldridge Z, Harrison Dening K. Dementia and comorbidities: A holistic approach. Pract Nurse. 2019; 49: 22-26.

78. Polson J, Croy S. Differentiating dementia, delirium and depression. Nurs Times. 2015;111: 1819.

79. Hogg J. Delirium. In: Oxford textbook of old age psychiatry. 2nd ed. Oxford: Oxford University Press; 2013.

80. British Geriatric Society. Depression among older people living in care homes: Collaborative approaches to treatment [Internet]. London: Royal College of Psychiatrists; 2018 [cited 2021 February 9th]. Available from: https://www.bgs.org.uk/sites/default/files/content/attachment/2018-09-

12/Depression\%20among\%20older\%20people\%20living\%20in\%20care\%20homes\%20report\% 202018.pdf.

81. Cheung EN, Benjamin S, Heckman G, Ho JM, Lee L, Sinha SK, et al. Clinical characteristics associated with the onset of delirium among long-term nursing home residents. BMC Geriatr. 2018; 18: 39.

82. Stewart R, Hotopf M, Dewey M, Ballard C, Bisla J, Calem M, et al. Current prevalence of dementia, depression and behavioural problems in the older adult care home sector: The South East London Care Home Survey. Age Ageing. 2014; 43: 562-567.

83. Page A, Etherton-Beer C, Seubert $\amalg$, Clark V, Hill X, King S, et al. Medication use to manage comorbidities for people with dementia: A systematic review. J Pharm Pract Res. 2018; 48: 356367.

84. Voss S, Black S, Brandling J, Buswell M, Cheston R, Cullum S, et al. Home or hospital for people with dementia and one or more other multimorbidities: What is the potential to reduce avoidable emergency admissions? The homeward project protocol. BMJ Open. 2017; 7: e016651.

85. Latham I, Atkinson T, Bray J, Evans S, Elliot V. Evaluation of the my home life admiral nurse role in the orders of St John care trust [Internet]. Worcester: University of Worcester; 2015 [cited 2021 March 10th]. Available from: http://eprints.worc.ac.uk/3827/.

86. Roberts $\mathrm{T}$, Bowers $\mathrm{B}$. How nursing home residents develop relationships with peers and staff: $\mathrm{A}$ grounded theory study. Int J Nurs Stud. 2015; 52: 57-67.

87. Kumar R, Chattu VK. What is in the name? Understanding terminologies of patient-centered, person-centered, and patient-directed care!. J Family Med Prim Care. 2018; 7: 487.

88. Cohen-Mansfield J, Lipson S. To hospitalize or not to hospitalize? That is the question: An analysis of decision making in the nursing home. Behav Med. 2006; 32: 64-70.

89. Goodman C, Dening T, Gordon AL, Davies SL, Meyer J, Martin FC, et al. Effective health care for older people living and dying in care homes: A realist review. BMC Health Serv Res. 2016; 16: 269.

90. Rivett $E$, Hammond L, West J. What influences self-perceived competence and confidence in dementia care home staff? A systematic review. Psychogeriatrics. 2019; 19: 440-456. 


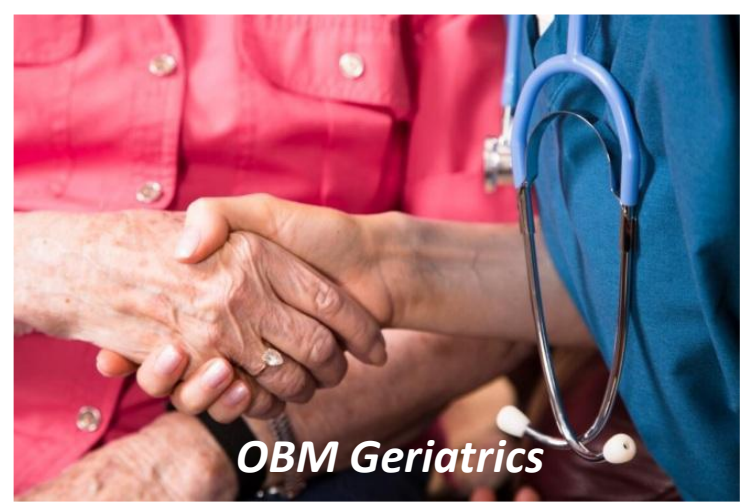

Enjoy $O B M$ Geriatrics by:

1. Submitting a manuscript

2. Joining in volunteer reviewer bank

3. Joining Editorial Board

4. Guest editing a special issue

For more details, please visit:

http://www.lidsen.com/journals/geriatrics 